\title{
The role of a cognitive factor in the prolongation of an induced visual afterimage
}

\author{
LEE D. SMITH and BENJAMIN WALLACE \\ Cleveland State University, Cleveland, Ohio 44115
}

\begin{abstract}
Induced visual afterimages endure for very short periods of time (about $15 \mathrm{sec}-2 \mathrm{~min}$ ). In an attempt to prolong the perceived duration of afterimages, an experiment was conducted to examine the roles of stimulus codability (the degree of intersubject agreement on the name of an inducing stimulus object) and stimulus complexity (the number of elements in the inducing object) on afterimage duration. We found that stimulus codability affected afterimage duration: A highly codable stimulus produced the most enduring afterimage. Stimulus complexity, on the other hand, did not affect afterimage duration. We conclude that, in addition to physiological factors that affect the production and prolongation of an afterimage, cognitive factors may play a role as well. One such factor may be stimulus codability.
\end{abstract}

When retinal photoreceptors are bleached by a pulse of light, the result is the production of a visual afterimage. If bleaching is complete, the afterimage should endure for about $25 \mathrm{~min}$, the approximate period of time required for bleached photoreceptors to regenerate (Brindley, 1962). However, this is rarely the case. Most experiments that have investigated various aspects of afterimage production report durations ranging from several seconds (Meudell \& Pease, 1968; Wallace, 1979a, 1979b; Wallace \& Smith, 1981) to several minutes (Hall \& Wilsoncroft, 1964; McGuinness \& Lewis, 1976). The variance in afterimage duration is generally attributable to the conditions of the inducing stimulus and/or to changes in background illumination against which the eventual afterimage is projected. For example, intense stimuli produce longer enduring afterimages than do dim stimuli (Brindley, 1962). Also, Hall and Wilsoncroft (1964) have reported that by simply flickering room lights "on" and "off," the duration of an afterimage significantly increased compared with a situation in which this flicker was not present.

The aforementioned experiments have manipulated variables that in all likelihood have demonstrated the role of physiological mechanisms (e.g., photoreceptors and photopigments) in the production and eventual prolongation of an afterimage. However, it is also possible that cognitive factors may play a role in the prolongation of an afterimage. The present experiment was conducted to determine if cognitive factors such as stimulus complexity and stimulus codability can help

This experiment is based in part upon a master's thesis by the senior author, conducted under the supervision of the junior author. A portion of these data were also presented at the meetings of the Midwestern Psychological Association, Detroit, May 1981. Reprint requests should be addressed to Benjamin Wallace, Department of Psychology, Cleveland State University, Cleveland, Ohio 44115. to increase afterimage duration. Complexity was defined in terms of the number of elements or lines in a stimulus pattern; the more elements (lines) present, the more complex the stimulus was considered to be. Codability was defined as a function of being able to verbally label the object of regard (Lachman, Shaffer, \& Henrikus, 1974). An object that can be easily labeled (e.g., "circle" for a round object) was considered to be highly codable.

\section{METHOD}

\section{Subjects}

Fortyeight volunteers from an introductory psychology class served as subjects. Each individual received extra course credit for participating. All subjects had normal, 20/20 uncorrected visual acuity in both eyes.

\section{Apparatus}

The experiment was conducted in a $3.1 \times 6.4 \mathrm{~m}$ completely lightproofed room. The stimuli to be observed were produced by a pulse (approximately $1 \mathrm{msec}$ in duration) from an electronic 2,000-beam candlepower/sec Vivitar (Model 273) flash unit. This unit was mounted on an adjustable stand that could be raised or lowered to permit the light source to be projected to the subject's eyes from an eye-level position. Stability of the subject's head during the experiment was maintained with a Marietta Instruments combination head-and-chin rest. Six stimuli that differed in level of stimulus codability and stimulus complexity were employed. These are illustrated in Figure 1. Each stimulus was produced by cutting a geometrical shape into a piece of thick, black tagboard. The tagboard was then mounted on the face of the flash unit such that when a pulse was initiated, a stimulus flash in the form of the shapes in Figure 1 was produced. Black electrical tape prevented light leakage from undesired locations on the flash unit.

\section{Design}

A 2 by 3 by 3 factorial design was employed. The first two factors were between-subjects factors and included stimulus codability (high or low) and stimulus complexity (high, moderate, or low). The third factor was a within-subjects variable consisting of three trials for stimulus observation. Eight subjects were randomly assigned to each of the six experimental conditions. 


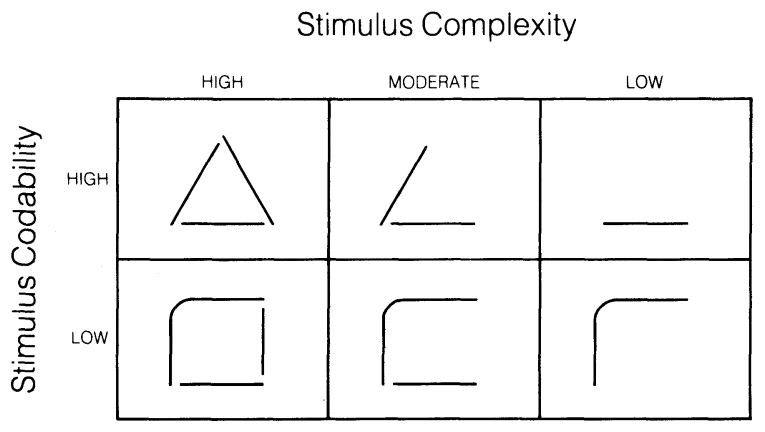

Figure 1. Stimuli employed and levels of codability and complexity.

\section{Procedure}

A pilot study was performed prior to the actual experiment that assessed the codability of the preselected stimuli to be employed. Illustrations were shown of six stimuli, and subjects were asked to identify each of them by writing a description near each object. The results showed that the names supplied for the lower stimuli in Figure 1 frequently differed from one respondent to the next. As a result, these stimuli were considered to be low in codability. Conversely, the upper stimuli in Figure 1 were judged to be highly codable, since there was general agreement among subjects concerning a common (and correct) name for each object. The most common descriptors and the percentage of respondents giving such a description for the three upper stimuli, from left to right, were as follows: "triangle" (85.9\%), "angle" (56.3\%), and "line" (62.9\%). The descriptions and percentage of response agreement for the lower stimuli, from left to right, were as follows: "square" (18.0\%), "C" (19.8\%), and "curve" (20.8\%).

After establishing the codability of the stimuli and making certain that they did differ in this regard, subjects who had not participated in the aforementioned identification task were individually led, blindfolded, to the experimental room and were seated in a chair. The experimenter turned off the room lights, and the blindfold was removed from the subject's eyes to permit dark adaptation for $15 \mathrm{~min}$. Following this period, the subject was instructed to gaze in the straight-ahead direction in space to observe the stimulus light. Subjects localized this position by fixating toward the voice of the experimenter. A visual fixation point was purposely avoided to eliminate any possible interfering influence of such on the eventual af terimage formation from the target pulse.

Before the flash was triggered, subjects were instructed to try as hard as possible not to blink. Also prior to receiving the flash, subjects were told that they would have to report when an afterimage was first visible and when the image was no longer visible. This report was tape-recorded, and subsequent duration assessments of the afterimage were determined by a stopwatch. Each subject was exposed to a total of three flashes, with a 15-min intertrial interval to permit the subject to readapt to the dark.

\section{RESULTS}

Two dependent measures were assessed in the experiment: afterimage duration and afterimage latency. Afterimage duration was defined as the period of time from when the subject first reported the appearance of an afterimage to the time the afterimage was reported as disappearing. Afterimage latency was defined as the period of time between the onset of the inducing stimu- lus and the first report of the appearance of an afterimage. Two separate analyses of variance were performed on these dependent measures as a function of stimulus codability (high or low) and stimulus complexity (high, moderate, or low).

With respect to afterimage duration, stimulus codability was found to have a significant effect $[F(1,42)=$ $6.88, \mathrm{p}<.025]$. The mean reported duration for the highly codable stimuli was $202.94 \mathrm{sec}(\mathrm{SD}=81.38)$, whereas that for the stimuli determined to be low in codability was $159.17 \mathrm{sec}(\mathrm{SD}=61.43)$. Stimulus complexity did not affect the duration of an afterimage $[F(2,42)=1.07]$. The mean duration values for the various experimental conditions were $198.31 \mathrm{sec}$ $(\mathrm{SD}=77.82)$ for the most highly complex stimuli, $171.92 \mathrm{sec}(\mathrm{SD}=75.57)$ for the moderately complex stimuli, $172.94 \mathrm{sec}(\mathrm{SD}=70.35)$ for the least complex stimuli. The interaction between the two independent variables (see Table 1) was also not significant $[\mathrm{F}(2,42)=$ $.08]$.

In reference to afterimage latency as a function of stimulus codability and stimulus complexity, neither factor affected this dependent measure. The mean latency values for the various experimental conditions are depicted in Table 2. Also, for neither dependent measure was there a significant trials effect.

\section{DISCUSSION}

Our results imply that highly codable stimuli tend to produce enduring afterimages. That is, if a subject can identify an afterimage by giving it a name, its duration appears to be prolonged. This may mean that afterimage prolongation requires the involvement of a cognitive component or components. Of course, the data reported here should be considered pilot data at best, and the evidence for the involvement of a cognitive component in afterimage perception is merely speculative at this time.

Stimulus complexity was not found to be significant in producing a prolongation of a perceived afterimage. A possible reason for this may be the result of the process of stimulus fragmentation. Previously, Evans (1965) reported that a straight line that is part of a more complex pattern has a high probability of either disappearing or remaining as a unit. And as has been suggested by Bennett-Clarke and Evans (1963) and Pritchard, Heron, and Hebb (1960), an afterimage of an outline of a square is initially visible in its entirety and then it may fragment, leaving one, two, or three lines visible, or it may disappear completely, only to reappear a little later. Possibly, a similar situation occurred with the stimuli employed here. For example, when an afterimage was generated from the triangle, it may have been visible in its entirety, initially. However, with the passage

Table 1

Mean Duration (in Seconds) of an Afterimage as a Function of Stimulus Complexity and Stimulus Codability

\begin{tabular}{|c|c|c|c|c|c|c|}
\hline \multirow{3}{*}{$\begin{array}{c}\text { Stimulus } \\
\text { Cod- } \\
\text { ability }\end{array}$} & \multicolumn{6}{|c|}{ Stimulus Complexity } \\
\hline & \multicolumn{2}{|c|}{ High } & \multicolumn{2}{|c|}{ Moderate } & \multicolumn{2}{|c|}{ Low } \\
\hline & Mean & SD & Mean & SD & Mean & SD \\
\hline $\begin{array}{l}\text { High } \\
\text { Low }\end{array}$ & $\begin{array}{l}223.88 \\
172.75\end{array}$ & $\begin{array}{l}80.02 \\
63.71\end{array}$ & $\begin{array}{l}194.63 \\
149.21\end{array}$ & $\begin{array}{l}64.48 \\
63.33\end{array}$ & $\begin{array}{l}190.33 \\
155.54\end{array}$ & $\begin{array}{l}74.19 \\
52.49\end{array}$ \\
\hline
\end{tabular}


Table 2

Mean Latency (in Seconds) of an Afterimage as a Function of Stimulus Complexity and Stimulus Codability

\begin{tabular}{|c|c|c|c|c|c|c|}
\hline \multirow{3}{*}{$\begin{array}{c}\text { Stimulus } \\
\text { Cod- } \\
\text { ability }\end{array}$} & \multicolumn{6}{|c|}{ Stimulus Complexity } \\
\hline & \multicolumn{2}{|c|}{ High } & \multicolumn{2}{|c|}{ Moderate } & \multicolumn{2}{|c|}{ Low } \\
\hline & Mean & SD & Mean & SD & Mean & SD \\
\hline High & 6.29 & 1.92 & 7.79 & 2.38 & 7.50 & 3.09 \\
\hline Low & 6.67 & 2.06 & 6.79 & 3.64 & 7.08 & 2.60 \\
\hline
\end{tabular}

of time, it may have fragmented, leaving only one or two lines visible. If the latter situation occurred, a distinction could not have been made between the fragmentations resulting from the triangle (the most complex stimulus employed) and the afterimages generated from the angle or the line. In some instances, the afterimage of the triangle may have appeared to be either an angle afterimage or a line afterimage. As a result, a distinction could not have been made between the three highly codable stimuli employed.

In summary, we believe we have identified at least one cognitive factor, stimulus codability, that may help to prolong the duration of a perceived afterimage. If cognition does play a role in prolonging an afterimage, as we believe it does, there may be additional cognitive factors that can produce the effect reported here. Hopefully, as this line of research continues, we shall discover if this is the case.

\section{REFERENCES}

Bennett-Clarke, H. C., \& Evans, C. R. Fragmentation of patterned targets when viewed as prolonged afterimages. Nature, 1963, 199, 1215-1216.

BrindLey, G. S. Two new properties of foveal afterimages and a photochemical hypothesis to explain them. Journal of Physiology, 1962, 164, 168-179.

Evans, C. R. Some studies of pattern perception using a stabilized retinal image. British Journal of Psychology, 1965, 52, 121-133.

Hall, R. J., \& Wilsoncroft, W. E. Prolonged visual afterimages. Psychonomic Science, 1964, 1, 267-268.

Lachman, R., Shaffer, J. P., \& Henrikus, D. Language and cognition: Effects of stimulus codability, name-word frequency, and age of acquisition of lexical reaction time. Journal of Verbal Learning and Verbal Behavior, 1974, 13, 613-625.

McGuinness, D., \& Lewis, I. Sex differences in visual persistence: Experiments on the Ganzfeld and afterimages. Perception, 1976, 5, 279-294.

Meudell, A., \& Pease, K. G. Influence of meaning on fragmentation of visual afterimages. Perceptual and Motor Skills, 1968, 27, 965-966.

Pritchard, R. M., Heron, W., \& HebB, D. O. Visual perception approached by the method of stabilized images. Canadian Journal of Psychology, 1960, 14, 67-77.

Wallace, B. Hypnotic susceptibility and the perception of afterimages and dot stimuli. American Journal of Psychology, 1979, 92, 681-691. (a)

Wallace, B. The role of iris pigmentation in the perception of an afterimage. Perception \& Psychophysics, 1979, 26, 469-471. (b)

Wallace, B., \& Smith, L. D. Sclera color and reports of afterimage persistence. Perception \& Psychophysics, 1981, 29, 277-279.

(Received for publication December 23, 1981.) 